\title{
The burden of HIV on Tuberculosis patients in the Volta region of Ghana from 2012 to 2015: implication for Tuberculosis control
}

\author{
Eric Osei ${ }^{1 *}$, Joyce Der², Richard Owusu², Philip Kofie ${ }^{3}$ and Wisdom Kudzo Axame ${ }^{2}$
}

\begin{abstract}
Background: The impact of HIV on TB, and the implications for TB control, has been acknowledged as a public health challenge. It is imperative therefore to assess the burden of HIV on TB patients as an indicator for monitoring the control efforts of the two diseases in this part of the world. This study aimed at determining the burden of HIV infection in TB patients.
\end{abstract}

Methods: We conducted a retrospective review of TB registers in five districts of the Volta Region of Ghana. Prevalence of TB/HIV co-infection was determined. Bivariate and multivariate logistic regression were used to identify the predictors of HIV infection among TB patients and statistical significance was set at $p$-value $<0.05$.

Results: Of the 1772 TB patients, 1633 (92.2\%) were tested for HIV. The overall prevalence of TB/HIV co-infection was (18.2\%; 95\% Cl: 16.4-20.1). The prevalence was significantly higher among females (24.1\%; 95\%Cl: 20.8-27.7), compared to males (15.1\%; $95 \% \mathrm{Cl}: 13.1-17.4)(p<0.001)$ and among children $<15$ years of age $(27.0 \%$; $95 \%$ Cl: 18.2-38.1), compared to the elderly $\geq 70$ years $(3.5 \%$; $95 \%$ Cl: 1.6-7.4) $(p<0.001)$. Treatment success rate was higher among patients with only TB (90\%; 95\% Cl: 88.1-91.5) than among TB/HIV co-infected patients (77.0\%; 95\% Cl: 71.7-81.7) $(p<0.001)$. Independent predictors of HIV infection were found to be: being female (AOR: $1.79 ; 95 \%$ Cl: $1.38-2.13$; $p<0.001$ ); smear negative pulmonary TB (AOR: 1.84; 95\% Cl: 1.37-2.47; $p<0.001$ ); and patients registered in Hohoe, Kadjebi, and Kpando districts with adjusted odds ratios of 1.69 (95\% Cl: 1.13-2.54; $p=0.011$ ), 2.29 (95\% Cl: 1.46-3.57; $p<0.001$ ), and 2.15 (95\% Cl: 1.44-3.21; $p<0.001$ ) respectively. Patients $\geq 70$ years of age and those registered in Keta Municipal were less likely to be HIV positive with odds ratios of 0.09 (95\% Cl: $0.04-0.26 ; p<0.001$ ) and 0.62 (95\% Cl: 0.38-0.99; $p=0.047$ ) respectively.

Conclusion: TB/HIV co-infection rate in five study districts of the Volta region is quite high, occurs more frequently in female patients than males; among smear negative pulmonary TB patients, and children $<15$ years of age. Findings also demonstrate that HIV co-infection affects TB treatment outcomes adversely. Strengthening the TB/HIV collaborative efforts is required in order to reduce the burden of co-infection in patients.

Keywords: TB, HIV, Co-infection, Burden, Volta region, Ghana

\footnotetext{
*Correspondence: eosei@uhas.edu.gh; erickosei15@gmail.com

${ }^{1}$ Department of Population and Behavioural Sciences, School of Public

Health, University of Health and Allied Sciences, Hohoe, Ghana

Full list of author information is available at the end of the article
} 


\section{Background}

Tuberculosis (TB) has existed for years and remains a major global public health problem. It causes ill-health in millions of people each year and in the year 2015, TB was among the top 10 causes of death worldwide, ranking above Human Immunodeficiency Virus/Acquired Immune Deficiency Syndrome (HIV/AIDS) as one of the leading causes of death from an infectious disease [1]. The 2015 estimates of the World Health Organization (WHO) showed that there were 10.4 million incident cases of TB worldwide of which, about $10 \%$ were coinfected with Human immuno-deficiency Virus (HIV) and about 1.4 million deaths, of which, 400,000 deaths were among people co-infected with HIV [1].

The HIV pandemic represents an important challenge to global TB control [2]. Many sub-Sahara African countries have borne the impact of the generalised HIV and tuberculosis epidemics, which have strained health systems and devastated populations in the region. Overall, $32 \%$ of TB cases were estimated to be co-infected with $\mathrm{HIV}$ in this region, which represents $74 \%$ of $\mathrm{TB}$ cases among people living with HIV worldwide [1].

TB/HIV co-infection poses widespread diagnostic, management and economic challenges. HIV infection has been reported to be associated with an increased risk of developing active TB by facilitating disease progression during primary $\mathrm{TB}$ infections or reactivation of latent infection by 20 -fold $[3,4]$. On the other hand, TB is a leading cause of death among people living with HIV [5], and TB/HIV co-infected patients, especially in the absence of antiretroviral therapy (ART), have significantly worse prognosis [6]. Additionally, HIV infection is associated with atypical clinical presentation of TB including smear negative pulmonary $\mathrm{TB}$, normal chest $\mathrm{X}$-ray and higher frequency of extra-pulmonary $\mathrm{TB}$ (EPTB); thus, challenging TB diagnosis in middle and low-income countries [7]. It is imperative therefore to periodically estimate the burden of TB/HIV co-infection as an indicator for monitoring the control efforts of the two diseases in this part of the world.

In Ghana, as in other sub-Saharan African countries, TB remains a major public health problem.

In 2015, the national prevalence was estimated at 356 per 100,000 population and incidence rate of 160 per 100,000 of the population [1].

The impact of HIV on TB, and the implications for TB and HIV control, have been acknowledged as a public health challenge in Ghana, as is the case in many other Sub-Saharan African countries. WHO classifies Ghana as having high burden of TB/HIV co-infection. According to the WHO, there were approximately 9900 incident cases of TB among HIV positive patients representing a rate of 36 per 100, 000 of the Ghanaian population in 2015 [1]. There has not been a systematic, nationwide study to analyse the prevalence of TB/HIV co-infection in Ghana. However, estimates show that the influence of HIV on TB has been increasing since 1989 while about $14 \%$ of TB cases could be attributed to HIV/AIDS. Hospital studies have also shown that the prevalence of HIV in TB patients is approximately $25-30 \%$ and that as many as $50 \%$ of patients with chronic cough could be HIV positive (Ghana Health Services: Guildelines for the clinical management of TB and HIV Co-infection in Ghana, unpublished).

Major progress has been made in global TB control following the widespread implementation of the Directly Observed Treatment Short-course (DOTS) strategy in many countries [8]. Full implementation of this strategy is however inadequate to control TB where HIV is fuelling the TB epidemic, and control of HIV infection must therefore become an important concern for National TB Programmes (NTP). In view of this, WHO updated its 2004 policy guideline that recommends offering routine HIV testing to patients with presumptive or diagnosed $\mathrm{TB}$ as a means of reducing the burden of HIV [2].

Since, June 2007, TB/HIV activities have been incorporated into the existing TB and HIV services in Ghana by ensuring routine ascertainment of HIV status in people with TB and vise visa in many health facilities and some communities in Ghana. Antiretroviral Therapy (ART) for all people with TB/HIV co-infection is also provided in all public and some private hospitals in the country as part of basic services for people living with TB/HIV [9].

In view of the rapidly changing face of the HIV epidemic and the emergence of an epidemic of TB/HIV co-infection, there is a pressing need for continuous evaluation of the magnitude of HIV infections among TB patients to help guide policies and strategies for scaling up TB/HIV collaboration activities. To this end, the current study aimed at assessing the burden of HIV infection among TB patients in the Volta Region of Ghana and to describe the association between HIV infection and characteristics of TB patients to provide a firm evidence base to underpin the planning and improvement of future collaborative TB/HIV activities.

\section{Methods}

\section{Study settings and design}

We conducted a retrospective study of all TB cases registered from 2012 to 2015 in five districts of Volta Region of Ghana. The districts were Ho, Hohoe and Kpando in the Middle zone; Kadjebi in the Northern zone and Keta in the Southern zone of the Volta region. Three districts were selected from the middle zone due to high population density compared with the other zones. The Volta region is the longest region in Ghana, and stretches from the Gulf of Guinea through nearly all the vegetational zones found in the country. The Region 
is divided into 25 administrative districts/municipalities with Ho as the Regional capital. Volta Region has a total of 377 health facilities serving a population of 2,789,211 with a growth rate of $2.5 \%$. The region is divided into three natural geographical belts namely the southern, middle and the northern belts. There are 44 DOTS centres and 41 diagnostic centres in the Region that provide TB diagnosis and treatment services to suspected clients. TB diagnosis, treatment, and monitoring are done as per the national tuberculosis control program (NTBCP) guidelines (Volta Regional Health Directorate: 2015 annual report, unpublished). All patients diagnosed with TB are also supposed to undergo HIV counselling and testing. Fig. 1 represents the map of the Volta region showing the study districts.

\section{Data source}

Data were extracted from the district TB register (TB 07). The register is a standardized document used by all district tuberculosis control programmes in Ghana. It is kept by the district TB focal person who goes round all treatment centres within the catchment area from time to time to update it by serially transferring patients' information from the facility TB registers into the district register. These information include patients' demographics, identifiers, type and category of $\mathrm{TB}$, initial and follow up sputum smear examination results, HIV test results, and treatment outcomes.

\section{Data handling and analysis}

Extracted data were entered into Microsoft Excel spread sheet for cleaning and exported into Stata Version 11.0 (Stata Corp, College Station, Texas, USA) for analysis. The excel spread sheet was designed to capture all important variables from the registers such as Age, Sex, Patient Type, Disease classification, Sputum Smear result, Treatment outcomes and HIV status. Welltrained public health trainees in the University did the data extraction. Cleaning was done to check for the consistency and completeness of the data set. Data were summarized using frequencies and proportions to describe the study population in relation to relevant variables. Prevalence of TB/HIV co-infection was estimated by using the number of TB patients tested positive for HIV as the numerator and the total number of TB patients tested for HIV as the denominator. Bivariate

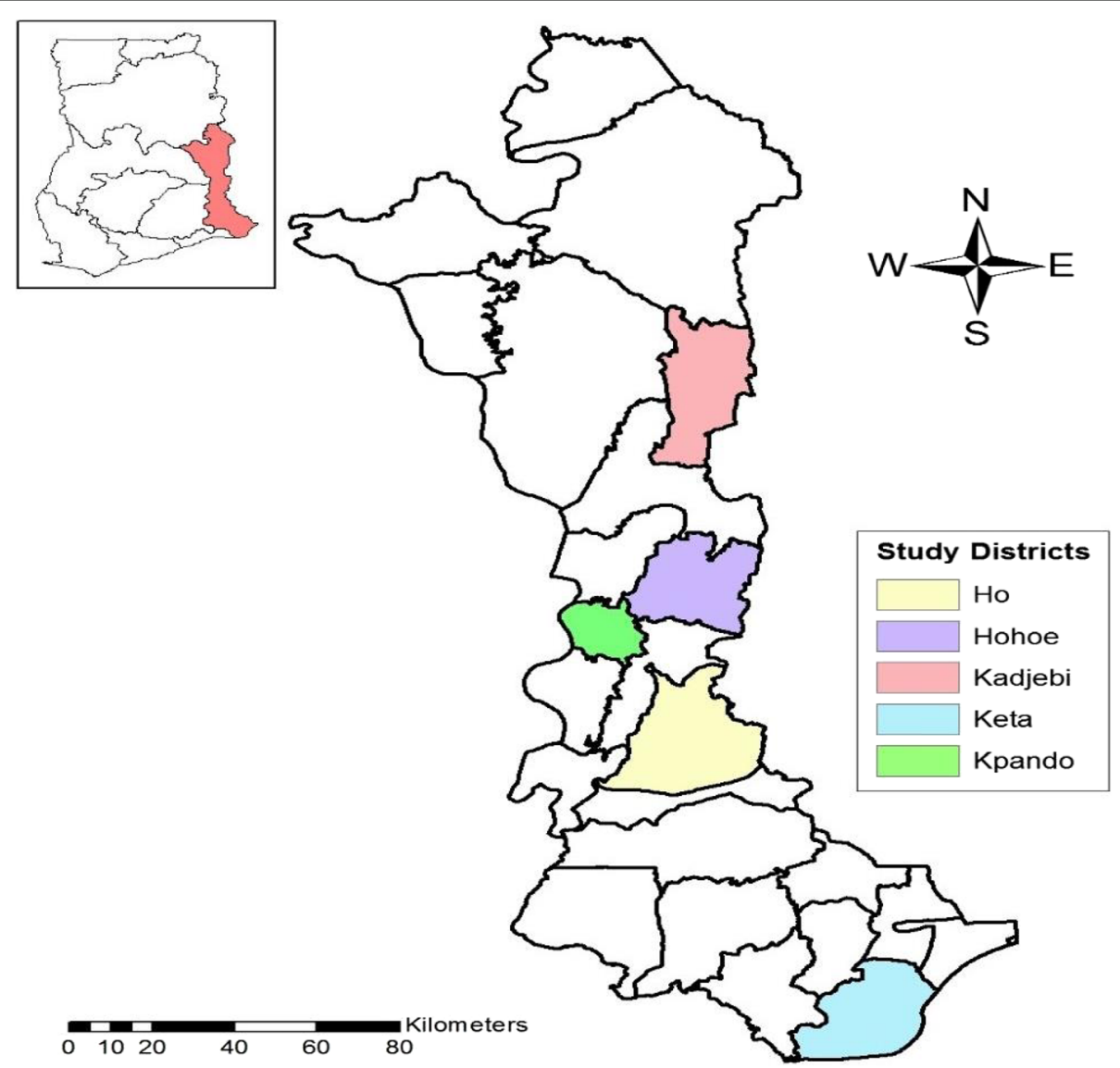

Fig. 1 Map of Volta Region showing study areas 
and multivariate logistic regression were used to identify significant predictors of HIV infection. The degree of association between dependent and independent variables was assessed using odds ratios (OR) with 95\% confidence intervals $(\mathrm{CI})$, and statistical significance was set at $p$-value $<0.05$.

\section{Definitions of terms}

New TB patient refers to a patient who has never had treatment for tuberculosis or who has taken antituberculosis drugs for less than 1 month.

Pulmonary Tuberculosis (PTB) refers to a patient with tuberculosis disease involving the lung parenchyma.

Smear positive PTB refers to a patient with at least one sputum smear positive for acid fast bacilli (AFB), or one sputum smear positive for AFB plus radiographic abnormalities consistent with active pulmonary tuberculosis; or one sputum specimen positive for AFB plus culture specimen positive for Mycobacterium tuberculosis.

Smear negative PTB refers to a patient with two negative sputum smears for AFB but radiological abnormality consistent with active $\mathrm{TB}$ or failure to respond to antibiotics treatment or one which health worker or clinician has diagnosed $\mathrm{TB}$ and decided to treat the patient with full course of anti TB drugs.

Extra pulmonary TB (EPTB) refers to patients with $\mathrm{TB}$ in any organ other than the lungs verified by histopathology.

\section{Ethical statement}

This study utilized routine service delivery data for the purposes of programme monitoring and evaluation. The data analysed did not include identifiers of the patients and was exempted from ethical approval. The University of Health and Allied Sciences, School of Public Health's scientific review committee ruled that this study do not require formal ethical approval.

\section{Results}

There were $1772 \mathrm{~TB}$ cases registered during the period under study. Of these, 1167 (65.9\%) were males and 605 (34.1\%) were females; 752 (42.4\%) were between 30 and 49 years of age; $87(4.9 \%)$ were $<15$ years, while 192 $(10.8 \%)$ were 70 years and above. The age range of patients was 1-100 years with median age (interquartile range (IQR)) of 43 (24). One thousand and twenty five (58\%) were smear positive pulmonary TB cases, 672 (37.9\%) were smear negative pulmonary $\mathrm{TB}$ cases, and 66 (3.7\%) extra-pulmonary TB cases. With respect to TB category, 1637 (92.4\%) were new TB cases, while 39 $(2.2 \%)$, and $30(1.7 \%)$ were relapse and treatment failure cases respectively. Of the total 1772 patients, 448 (25.3\%) were registered in Ho Municipal, while 395 $(22.3 \%)$ and 275 (15.5\%) were registered in Hohoe and
Kadjebi respectively. Kpando and Keta recorded 327 (18.5\%) cases each (Table 1).

\section{HIV testing and prevalence of HIV among TB patients}

Of the 1772 TB cases registered during the study period, 1633 (92.2\%) were tested for HIV. The proportion of TB cases tested for HIV was more than $90 \%$ for all districts except Ho and Kadjebi where $85 \%$ and $81.8 \%$ of cases registered during the period were tested respectively. Of the 1633 cases tested for HIV, 297 (18.2\%; 95\% CI: 16.4-20.1) were HIV positive. The prevalence was highest in Kpando municipal (26.0\%; 95\% CI: $21.5-31.2)$ followed by Kadjebi district (24.9\%;

Table 1 General characteristics of study subjects, 2012-2015

\begin{tabular}{|c|c|c|c|c|c|}
\hline Characteristic & $\begin{array}{l}2012 \\
(N=579) \\
n(\%)\end{array}$ & $\begin{array}{l}2013 \\
(N=433) \\
n(\%)\end{array}$ & $\begin{array}{l}2014 \\
(N=340) \\
n(\%)\end{array}$ & $\begin{array}{l}2015 \\
(N=420) \\
n(\%)\end{array}$ & $\begin{array}{l}\text { All years } \\
(N=1772) \\
\mathrm{n}(\%)\end{array}$ \\
\hline \multicolumn{6}{|c|}{$\overline{\text { Age group (years) }}{ }^{a}$} \\
\hline $0-14$ & $43(7.4)$ & $22(5.1)$ & $13(3.8)$ & $9(2.1)$ & $87(4.9)$ \\
\hline $15-29$ & $98(16.9)$ & $69(15.9)$ & 49 (14.4) & $60(14.3)$ & $276(15.6)$ \\
\hline $30-49$ & $240(41.5)$ & $179(41.3)$ & $154(45.3)$ & $179(42.6)$ & $752(42.4)$ \\
\hline $50-69$ & $132(22.8)$ & $116(26.8)$ & $93(27.4)$ & $122(29.1)$ & $463(26.1)$ \\
\hline$\geq 70$ & $66(11.4)$ & 47 (10.9) & $31(9.1)$ & $48(11.4)$ & $192(10.9)$ \\
\hline \multicolumn{6}{|l|}{ Sex } \\
\hline Male & $374(64.6)$ & $276(63.7)$ & $221(65.0)$ & $296(70.5)$ & $1167(65.9)$ \\
\hline Female & $205(35.4)$ & $157(36.3)$ & $119(35.0)$ & $124(29.5)$ & $605(34.1)$ \\
\hline \multicolumn{6}{|l|}{ Patient category ${ }^{b}$} \\
\hline New & $547(94.5)$ & $393(90.8)$ & $322(94.7)$ & $375(89.3)$ & $1637(92.4)$ \\
\hline $\begin{array}{l}\text { Transferred } \\
\text { in }\end{array}$ & $1(0.2)$ & $3(0.7)$ & $1(0.3)$ & 0 & $5(0.3)$ \\
\hline $\begin{array}{l}\text { Return } \\
\text { after default }\end{array}$ & $5(0.9)$ & $3(0.7)$ & $1(0.3)$ & $7(1.7)$ & $16(0.9)$ \\
\hline $\begin{array}{l}\text { Treatment } \\
\text { failure }\end{array}$ & $4(0.7)$ & $9(2.1)$ & $5(1.5)$ & $12(2.9)$ & $30(1.7)$ \\
\hline Relapse & $6(1.0)$ & $11(2.5)$ & $10(2.9)$ & $12(2.9)$ & $39(2.2)$ \\
\hline Other & $15(2.6)$ & $15(3.2)$ & $1(0.3)$ & $3(0.7)$ & $33(1.9)$ \\
\hline \multicolumn{6}{|l|}{ TB classification ${ }^{c}$} \\
\hline $\begin{array}{l}\text { Pulmonary } \\
\text { positive }\end{array}$ & $262(45.3)$ & $240(55.4)$ & $224(65.9)$ & $299(71.2)$ & $1025(57.8)$ \\
\hline $\begin{array}{l}\text { Pulmonary } \\
\text { negative }\end{array}$ & $279(48.2)$ & $183(42.3)$ & 109 (32.1) & $101(24.1)$ & $672(37.9)$ \\
\hline $\begin{array}{l}\text { Extra- } \\
\text { pulmonary }\end{array}$ & $37(6.4)$ & $10(2.3)$ & $7(2.1)$ & $12(2.9)$ & $66(3.7)$ \\
\hline \multicolumn{6}{|c|}{ Treatment District } \\
\hline $\mathrm{Ho}$ & $194(33.5)$ & $123(28.4)$ & $67(19.7)$ & $64(15.2)$ & $448(25.3)$ \\
\hline Hohoe & $127(21.9)$ & 97 (22.4) & 95 (27.9) & 76 (18.1) & $395(22.3)$ \\
\hline Kadjebi & $51(8.8)$ & $91(21.0)$ & $43(12.7)$ & $90(21.4)$ & $275(15.5)$ \\
\hline Keta & $118(20.4)$ & $47(10.9)$ & $53(15.6)$ & $101(26.0)$ & $327(18.5)$ \\
\hline Kpando & 89 (15.4) & 75 (17.3) & $82(24.1)$ & 81 (19.3) & $327(18.5)$ \\
\hline
\end{tabular}

Missing values for age, patient category ${ }^{\mathrm{b}}$, and TB classification ${ }^{\mathrm{c}} ; 2$ (0.1\%); $12(0.7 \%)$; and $9(0.5 \%)$ respectively 
95\% CI: 19.7-30.9) and lowest in Keta municipal (10.8\%; 95\% CI: 7.9-14.7) as shown in Table 2 and Fig. 2.

Prevalence of TB/HIV co-infection stratified by sex and age The overall prevalence of TB/HIV co-infection was significantly higher (24.1\%; 95\% CI: 20.8-27.7) among females compared to males (15.1\%; 95\% CI: 13.1-17.4) $(p<0.001)$. With regards to age, the prevalence was highest (27.0\%; 95\% CI: 18.2-38.1) among patients $<15$ years of age and lowest (3.5\%; 95\% CI: 1.6-7.4) among patients $\geq 70$ years $(p<0.001)$. Fig. 3 shows the trend of prevalence of TB/HIV co-infection stratified by sex whereas Fig. 4 represents the prevalence of TB/HIV by age groups.

\section{Trends of TB/HIV co-infection stratified by district}

The prevalence of TB/HIV co-infection was stable during the four-year study period. In the year 2012, 105 (19.4\%; 95\% CI: 16.3-22.9) TB patients were positive for HIV. The prevalence remained fairly stable (19.8\%; 95\% CI: 16.0-24.2) in the year 2013 and decreased to $15.8 \%$ (95\% CI: $12.3-20.1$ ) in 2014 and subsequently rose slightly to $17.0 \%$ (95\% CI: $13.6-21.1 ; p=0.424$ ) in the year 2015 .

\section{Treatment outcomes of TB only and TB/HIV co-infected patients}

Treatment outcomes significantly differed among TB cases and TB/HIV co-infected patients. Nearly 90\% (95\% CI: 88.1-91.5) of only TB cases evaluated were successfully treated, compared to $77 \%$ (95\% CI: 71.7-81.7) among TB/HIV co-infected patients $(p<0.001)$. TB/HIV co-infected patients were about 3 times more likely to die before completing treatment compared to TB only patients. Defaulter rate was also highest $(9 ; 3.3 \%)$ among co-infected patients compared to $21(1.7 \%)$ among patients with TB only. However, treatment failure rate was about 2 times more among patients with TB only compared to TB/HIV co-infected patients as shown in Table 3.

Table 2 HIV testing and prevalence of HIV among TB patients from 2012 to 2015

\begin{tabular}{lllll}
\hline District & $\begin{array}{l}\text { \#TB cases } \\
\text { registered }\end{array}$ & $\begin{array}{l}\text { HIV test } \\
\mathrm{n}(\%)\end{array}$ & $\begin{array}{l}\text { HIV Positive } \\
\mathrm{n}(\%)\end{array}$ & $95 \% \mathrm{Cl}$ \\
\hline Ho & 448 & $381(85.0)$ & $52(13.7)$ & $10.6-17.5$ \\
Hohoe & 395 & $389(98.5)$ & $72(18.5)$ & $15.0-22.7$ \\
Kadjebi & 275 & $225(81.8)$ & $56(24.9)$ & $19.7-30.9$ \\
Keta & 327 & $323(98.5)$ & $35(10.8)$ & $7.9-14.7$ \\
Kpando & 327 & $315(96.3)$ & $82(26.0)$ & $21.5-31.2$ \\
All Districts & $\mathbf{1 7 7 2}$ & $\mathbf{1 6 3 3 ( 9 2 . 2 )}$ & $\mathbf{2 9 7}(\mathbf{1 8 . 2 )}$ & $\mathbf{1 6 . 4 - 2 0 . 1}$ \\
\hline
\end{tabular}

\section{Predictors of HIV infection among TB patients}

In this study, it was observed that female $\mathrm{TB}$ patients were significantly more likely to be HIV positive compared to males (OR: 1.79; 95\% CI: $1.38-2.31 ; P<0.001$ ) on bivariate analysis. Also patients' age, TB classification, and treatment district were significantly associated with positive HIV result.

In the adjusted analysis, patients who were $\geq 70$ years old had 91\% lower odds of being infected with HIV (AOR: 0.09; 95\% CI: 0.04-0.26; $P<0.001$ ) than patients who were less than 15 years old. Additionally, female TB patients were about 2 times more likely to be HIV positive compared to male patients (AOR: 1.89; 95\% CI: 1.44-2.49; $P<0.001$ ). With regards to TB classification, smear negative pulmonary TB patients were $84 \%$ more likely to be HIV positive (AOR: 1.84; 95\% CI: 1.37-2.47; $P<0.001)$ than smear positive pulmonary TB patients. However, the odds of HIV infection was not significantly different among extra-pulmonary TB patients compared to the reference group. TB Patients registered in Keta municipality had $62 \%$ lower odds of being HIV positive (AOR: 0.62; 95\% CI: 0.38-0.99; $P=0.047$ ), compared to those registered in Ho municipality. Conversely, patients registered in Hohoe, Kadjebi, and Kpando were more likely to be HIV positive (AOR: 1.69; 95\% CI: 1.13-2.54; $P=0.01$ ), (AOR: 2.29; 95\%CI: 1.46-3.57; $P<0.001$ ), (AOR: $2.15 ; 95 \%$ CI: $1.44-3.21 ; P<0.001$ ) respectively compared to the reference district (Table 4 ).

\section{Discussion}

HIV testing for TB patients and TB/HIV co-infection rates

Systematic screening for HIV among TB patients is recommended by WHO as an essential component of the TB care package. This study established that more than 9 in 10 TB patients notified during the period had documented HIV test result, higher than the WHO's global estimate of $55 \%$ in 2015 and that of the African Regions (81\%) [1]. This shows that HIV screening practices among TB patients is good in this part of the world and should be sustained. Similar finding was reported in a study in Ethiopia [10].

Regional and countries prevalence studies on TB/HIV co-infection showed varied values ranging between 2.9 and $72.3 \%$, with pooled prevalence of $23.5 \%$ [11]. The overall HIV seroprevalence in TB patients in this study is higher than the current global estimate of $15 \%$ but much lower than the estimate from the African Region (36\%) [1] and the national average of $24 \%$ [12] but is comparable to findings from studies done in India (18.9\%) and Brazil (19\%) [13, 14].

Overall, the global prevalence of TB/HIV co-infection has been falling since 2008 [1]. Conversely, this study identified a stable TB/HIV co-infection in the study districts during the years 2012 to 2015 . This suggests that 


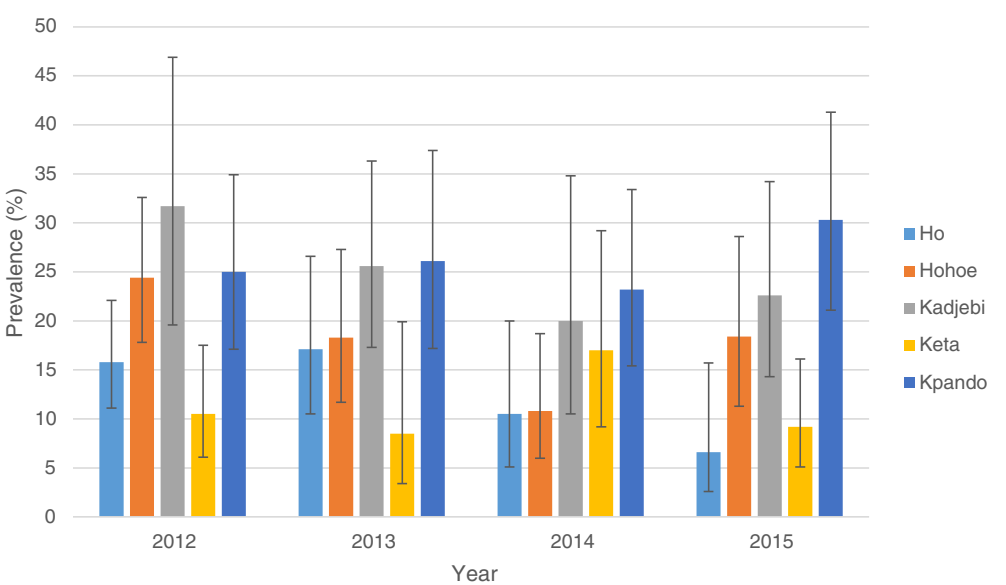

Fig. 2 Annual prevalence of TB/HIV co-infection stratified by district

additional efforts to strengthen TB/HIV collaborative activities are required in order to reduce the burden of HIV in TB patients. However, given that we used only 4 years in our analysis, we recommend further studies which incorporate data of several years before a firm conclusion can be drawn.

\section{Predictors of HIV infection in TB patients}

In this study, TB/HIV coinfection rate was significantly higher in female patients than in males. This finding is consistent with a number of studies that showed that females bear a disproportionate burden of HIV infections in sub-Saharan Africa [15-18]. The factors contributing to this could include lower socioeconomic position of women [18] as well as biology, sexual behaviour and socially constructed gender differences between men and women in roles and responsibilities, access to resources and decision-making power $[18,19]$. Our finding is however contrary to findings from a study in Northwest Ethiopia [10] but similar to report from Northeastern Ethiopia [20].

A high rate of TB/HIV co-infection was also observed in patients $<15$ years of age. This is in contrast to several studies that have shown TB/HIV coinfection rates to be higher in persons aged $25-45$ years $[10,21,22]$ representing the sexually active age group. The high prevalence in persons $<15$ years could imply early indulgence in sexual activities by this age group in the study districts but this needs to be thoroughly investigated.

Among patients with pulmonary TB, those with sputum smear negative were about 2 times more likely to be co-infected with HIV. This finding concords with that

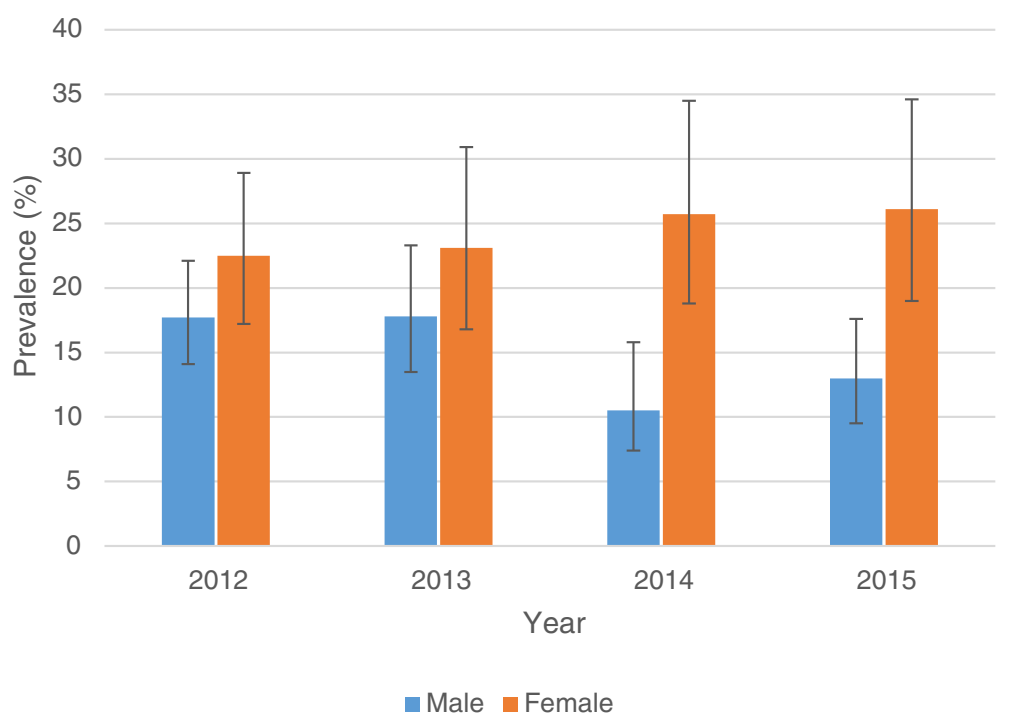

Fig. 3 Annual prevalence of TB/HIV co-infection stratified by sex 


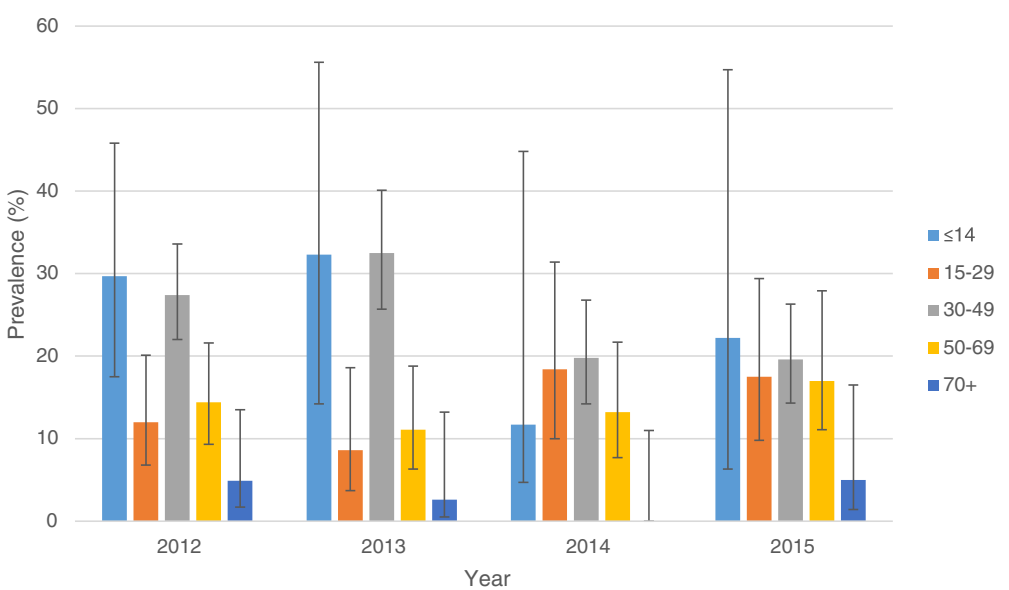

Fig. 4 Annual prevalence of TB/HIV stratified by age group

of a previous report, which showed that, in patients with HIV/AIDS, especially in the late stage of HIV infection, TB is often atypical in presentation and has low sputum smear positivity in pulmonary $\mathrm{TB}$, which could result in delayed diagnosis of TB [23].

\section{Treatment outcomes of HIV-positive and HIV-negative TB patients}

TB/HIV co-infected patients in this study had more unsuccessful treatment outcomes than patients with TB only and were more likely to die before completing treatment. Unsuccessful treatment outcomes associated with TB/HIV coinfection have been shown by several studies [21-24]. The reason for the poor outcomes in this group could be due to drug interactions between the rifamycins (rifampin or rifabutin) and some antiretroviral agents [25] as well as malabsorption of anti-TB drugs among patients with advanced HIV [26], leading to low serum concentrations of drugs and therefore to unsuccessful treatment outcomes [27]. In addition, the high death rate among TB/HIV co-infected patients could be due to alternation of the clinical manifestation of TB and lack of a rapid and sensitive TB diagnostic test for diagnosing TB in HIV patients leading to delayed diagnosis and treatment [28-30] that could eventually lead to death. The clinical alteration of TB in HIV-positive patients could also explain they were more likely to be smear negative as seen in this study. In contrast, treatment failure rate was twice more higher in patients with only TB compared to TB/HIV co-infected patients. Several reasons could account for this; it could be that some TB patients resort to traditional/herbal treatment, poor adherence to treatment and some could even have drug resistant TB [31, 32] and therefore will not respond to first line anti-TB drugs but this needs to be evaluated further in another study.

This study was retrospective in design and based only on data that was available in public health records. We could not independently corroborate the accuracy of these records, nor could we collect additional data needed to confirm or refute our findings. In particular we could not differentiate between TB/HIV co-infected patients on ART and those not on ART, and therefore, we could not assess its effect on our findings. Though a limitation, it calls for linkage of databases between TB and HIV control programs to ensure completeness of data for TB/HIV co-infected patients at all levels of the health care system. This will improve analysis of data that can provide accurate information for effective planning of targeted interventions. Despite this limitation, the study did provide useful information on the burden of HIV among TB patients in five districts of the Volta region. Findings may be useful to TB program managers and policy makers in implementing interventions to improve control of these infections.

Table 3 Treatment outcomes among patients with TB only compared to TB/HIV co-infected patients

\begin{tabular}{llllll}
\hline Type of patient & Successful & Unsuccessful & & Total evaluated N (\%) \\
\cline { 3 - 5 } & Cured + completed $n(\%)$ & Died $\mathrm{n}(\%)$ & Defaulted $\mathrm{n}(\%)$ & Treatment Failure $\mathrm{n}(\%)$ & \\
\hline TB only & $1096(89.9)$ & $77(6.3)$ & $21(1.7)$ & $25(2.1)$ & $1219(77.9)$ \\
TB/HIV & $208(77.0)$ & $50(18.5)$ & $9(3.3)$ & $3(1.1)$ & $270(22.1)$ \\
Total & $1304(87.6)$ & $127(8.5)$ & $30(2.0)$ & $28(1.2)$ & $1489(100)$ \\
\hline$P<0.001$ & &
\end{tabular}

$p<0.001$ 
Table 4 Predictors of HIV among TB patients in Volta Region, Ghana from 2012 to 2015

\begin{tabular}{|c|c|c|c|c|c|}
\hline Characteristic & TB/HIV n (\%) & OR $(95 \% \mathrm{Cl})$ & $p$-value & AOR $(95 \% \mathrm{Cl})$ & $p$-value \\
\hline Age group (years) & & & 0.001 & & \\
\hline $0-14$ & $20(27.0)$ & 1 & & 1 & \\
\hline $15-29$ & $35(13.7)$ & $0.43(0.23-0.79)$ & & $0.52(0.27-1.01)$ & 0.054 \\
\hline $30-49$ & $176(25.0)$ & $0.90(0.53-1.55)$ & & $1.15(0.65-2.05)$ & 0.632 \\
\hline $50-69$ & $60(14.1)$ & $0.44(0.25-0.79)$ & & $0.52(0.28-0.96)$ & 0.036 \\
\hline$\geq 70$ & $6(3.5)$ & $0.09(0.04-0.26)$ & & $0.09(0.04-0.26)$ & 0.001 \\
\hline Sex & & & 0.001 & & \\
\hline Male & $162(15.1)$ & 1 & & 1 & \\
\hline Female & $135(24.1)$ & $1.79(1.38-2.31)$ & & $1.89(1.44-2.49)$ & 0.001 \\
\hline Patient category & & & 0.931 & & \\
\hline New & $275(93.2)$ & 1 & & & \\
\hline Transferred in & 0 & - & & & \\
\hline Defaulter & $3(1.0)$ & $1.50(0.40-5.58)$ & & & \\
\hline Treatment failure & $6(2.0)$ & $1.13(0.46-2.78)$ & & & \\
\hline Relapse & $7(2.4)$ & $1.09(0.47-2.51)$ & & & \\
\hline Other & $4(1.8)$ & $0.72(0.25-2.09)$ & & & \\
\hline TB classification & & & 0.0015 & & \\
\hline Pulmonary positive & $151(15.8)$ & 1 & & 1 & \\
\hline Pulmonary negative & $139(22.5)$ & $1.54(1.19-1.99)$ & & $1.84(1.37-2.47)$ & 0.001 \\
\hline Extra-pulmonary & $5(10.4)$ & $0.62(0.24-1.59)$ & & $0.58(0.22-1.55)$ & 0.279 \\
\hline Treatment District & & & 0.001 & & \\
\hline Ho & $52(13.7)$ & 1 & & 1 & \\
\hline Hohoe & $72(18.5)$ & $1.44(0.97-2.12)$ & & $1.69(1.13-2.54)$ & 0.011 \\
\hline Kadjebi & $56(24.9)$ & $2.09(1.38-3.19)$ & & $2.29(1.46-3.57)$ & 0.001 \\
\hline Keta & $35(10.8)$ & $0.77(0.49-1.21)$ & & $0.62(0.38-0.99)$ & 0.047 \\
\hline Kpando & $82(26.0)$ & $2.23(1.51-3.28)$ & & $2.15(1.44-3.21)$ & 0.001 \\
\hline Year registrated & & & 0.419 & & \\
\hline 2012 & 105 (19.4) & 1 & & & \\
\hline 2013 & $73(19.8)$ & $1.02(0.73-1.43)$ & & & \\
\hline 2014 & $53(15.8)$ & $0.78(0.54-1.12)$ & & & \\
\hline 2015 & $66(17.0)$ & $0.85(0.61-1.19)$ & & & \\
\hline
\end{tabular}

$O R$ odds ratio, $A O R$ adjusted odds ratio

\section{Conclusion}

The proportion of TB/HIV co-infection in the study districts was quite high and associated with females, persons aged $<15$ years. Additionally, HIV-negative TB patients had better treatment outcomes compared to HIV-positive patients. There is the need for targeted interventions like awareness creation for females and persons aged $<15$ years. Factors accounting for unsuccessful treatment outcomes in co-infected patients should be identified and addressed to improve treatment outcomes and prevent deaths in this vulnerable population. Also, factors responsible for treatment failure in HIV-negative TB patients in this setting should be investigated.

\section{Abbreviation}

AFB: Acid fast bacilli; AIDS: Acquired immune deficiency syndrome; ART: Antiretroviral therapy; Cl: Confidence interval; DOTS: Directly observed treatment short-course; HIV: Human immune-deficiency virus; NTP: National TB control programme; TB: Tuberculosis; WHO: World Health Organization

\section{Acknowledgements}

The authors gratefully acknowledge the following persons who collected data for the study: Mr. Emmanuel Sasu Ampadu, Ms. Dorcass Yayra Gidisu, Mr. Samuel Opong, Ms. Eva Peaslip Kemedo, and Mr. Mark Arhin, all students of University of Health and Allied Sciences, Hohoe, Ghana. We are also grateful to all District Directors of Health Services in the study areas for granting as access to the data.

Funding

This study received no specific funding. 


\section{Availability of data and materials}

Data used for this study is available on request.

\section{Authors' contributions}

EO conceived and design the study and wrote the first draft of the manuscript. RO analysed data. WKA contributed in data analysis. PK contributed in literature review. JD contributed in reviewing literature and drafting of the manuscript. Al authors read and approved the final manuscript.

\section{Ethics approval and consent to participate}

The University of Health and Allied Sciences, School of Public Health's scientific review committee ruled that this study do not require formal ethical approval.

\section{Consent for publication}

Not applicable.

\section{Competing interests}

The authors declare that they have no competing interest.

\section{Publisher's Note}

Springer Nature remains neutral with regard to jurisdictional claims in published maps and institutional affiliations.

\section{Author details}

Department of Population and Behavioural Sciences, School of Public Health, University of Health and Allied Sciences, Hohoe, Ghana. ${ }^{2}$ Department of Epidemiology and Biostatistics, School of Public Health, University of Health and Allied Sciences, Hohoe, Ghana. ${ }^{3}$ Department of Family and Community Health, School of Public Health, University of Health and Allied Sciences, Hohoe, Ghana.

Received: 15 February 2017 Accepted: 10 July 2017

Published online: 19 July 2017

\section{References}

1. WHO. Global tuberculosis report, 2015. World health organization, Geneva, Switzerland. 2016; WHO/HTM/TB/2015.22.

2. WHO. WHO policy on collaborative TB/HIV activities: guidelines for national programmes and other stakeholders. Geneva: World Health Organization; 2013. WHO/HTM/TB/2012.1; WHO/HIV/2012.1

3. Allen S, Batungwanayo J, Kerlikowske K, Lifson AR, Wolf W, Granich R, et al. Two-year incidence of tuberculosis in cohorts of HIV-infected and uninfected urban Rwandan women. Am Rev Respir Dis. 1992:146(6):1439-44.

4. Selwyn PA, Hartel D, Lewis VA, Schoenbaum EE, Vermund SH, Klein RS, et al. A prospective study of the risk of tuberculosis among intravenous drug users with human immunodeficiency virus infection. N Engl J Med. 1989; 320(9):545-50.

5. Corbett EL, Watt CJ, Walker N, Maher D, Williams BG, Raviglione MC, et al. The growing burden of tuberculosis: global trends and interactions with the HIV epidemic. Arch Intern Med. 2003;163(9):1009-21.

6. Kang'ombe $C T$, Harries AD, Ito K, Clark T, Nyirenda TE, Aldis W, et al. Longterm outcome in patients registered with tuberculosis in Zomba Malawi: mortality at 7 years according to initial HIV status and type of TB. Int J Tuberc Lung Dis. 2004;8(7):829-36.

7. Centers for Diseases Control and Prevention. CDC grand rounds: the TB/HIV syndemic. MMWR. 2012;61(26):484-9.

8. WHO. Implementing the WHO Stop TB Strategy: a handbook for national tuberculosis control programmes. Geneva, World Health Organization. 2008. WHO/HTM/TB.2008.401.

9. Ansa GA, et al. Assessing the impact of TB/HIV services integration on TB treatment outcomes and their relevance in TB/HIV monitoring in Ghana. Infect Dis Poverty. 2012;1:13.

10. Tarekegne D, Jemal M, Atanaw T, Ebabu A, Endris M, Moges F, Tessema B, Deressa T. Prevalence of human immunodeficiency virus infection in a cohort of tuberculosis patients at Metema hospital, Northwest Ethiopia: a 3 years retrospective study. BMC Res Notes. 2016;9:192.

11. Gao J, Zheng P, Fu H. Prevalence of TB/HIV Colnfection in Countries Except China: A Systematic Review and Meta-Analysis. PLoS ONE, 2013, 8(5):

12. WHO Reports, 2014. TB country profiles. http://www.who.int/tb/country/ data/profiles/en/. Accessed on 4/10/2016.
13. Kamath R, Sharma V, Pattanshetty S, Hegde M, Chandrasekaran V. HIV-TB coinfection: clinico-epidemiological determinants at an antiretroviral therapy center in southern India. Lung India. 2013;30(4):302-6.

14. Prado D, Miranda A, Souza F, Dias E, Sousa L, Arakaki-Sanchez D, Sanchez M, Golu J, Maciel J. Factors associated with tuberculosis by HIV status in the Brazilian national surveillance system: a cross sectional study. BMC Infect Dis. 2014;14:415.

15. Magadi MA. Understanding the gender disparity in HIV infection across countries in sub-Saharan Africa: evidence from the demographic and health surveys. Sociol Health IIIn. 2011;33(4):522-39.

16. Sia D, Onadja Y, Nandi A, Foro A, Brewer T. What lies behind gender inequalities in HIV/AIDS in sub-Saharan African countries: evidence from Kenya, Lesotho and Tanzania. Health Policy Plan. 2014;29(7):938-49.

17. Sia D, Onadja Y, Hajizadeh M, Jody Heymann S, Brewer TF, Nandi A. What explains gender inequalities in HIV/AIDS prevalence in sub-Saharan Africa? Evidence from the demographic and health surveys. BMC Public Health. 2016;16:113.

18. Madkan VK, Giancola AA, Sra KK, Tyring SK. Sex differences in the transmission, prevention and disease manifestations of sexually transmitted diseases. Arch Dermatol. 2006;142(3):365-70.

19. World Health Organization. Gender and HIV / AIDS Gender and Health. Geneva: WHO Department of Gender and Women's Health; 2003.

20. Mekonnen D, Derbie A, Desalegn E. TB/HIV co-infections and associated factors among patients on directly observed treatment short course in Northeastern Ethiopia: a 4 years retrospective study. BMC Res Notes. 2015;8:666.

21. van der Werf MJ, Ködmön C, Zucs P, Hollo V. Amato-Gauci AJ, Pharris A. Tuberculosis and HIV coinfection in Europe: looking at one reality from two angles. AIDS. 2016;30(18):2845-53.

22. Sanchez M, Bartholomay P, Arakaki-Sanchez D, Enarson D, Bissell K, Barreira D, et al. Outcomes of TB treatment by HIV status in National Recording Systems in Brazil, 2003-2008. PLoS One. 2012;7(3):e33129.

23. do Prado TN, Miranda AE, de Souza FM, dos Santos Dias E, Sousa LKF, Arakaki-Sanchez D, Sanchez MN, Golub JE, Maciel EL. Factors associated with tuberculosis by HIV status in the Brazilian national surveillance system: a cross sectional study. BMC Infect Dis. 2014:14:415.

24. Burman WJ, Jones BE. Treatment of HIV-related tuberculosis in the era of effective antiretroviral therapy. Am J Respir Crit Care Med. 2001:164:7-12.

25. Holland DP, Hamilton CD, Weintrob AC, Engemann JJ, Fortenberry ER, Peloquin CA, Stout JE. Therapeutic drug monitoring of antimycobacterial drugs in patients with both tuberculosis and advanced human immunodeficiency virus infection. Pharmacotherapy. 2009;29:503-10.

26. Karo B, Krause G, Hollo V, van der Werf MJ, Castell S, Hamouda O, Haas W. Impact of HIV infection on treatment outcome of tuberculosis in Europe. AIDS. 2016:30(7):1089-98.

27. Sterling TR, Pham PA, Chaisson RE. HIV infection-related tuberculosis: clinical manifestations and treatment. Clin Infect Dis. 2010:50:S223-30.

28. Epstein MD, Schluger NW, Davidow AL, Bonk S, Rom WN, Hanna B. Time to detection of mycobacterium tuberculosis in sputum culture correlates with outcome in patients receiving treatment for pulmonary tuberculosis. Chest. 1998;113:379-86.

29. Osei E, Akweongo P, Binka F. Factors associated with DELAY in diagnosis among tuberculosis patients in Hohoe municipality, Ghana. BMC Public Health. 2015;15:721

30. Sawadogo B, Tint KS, Tshimanga M, Kuonza L, Ouedraogo L. Risk factors for tuberculosis treatment failure among pulmonary tuberculosis patients in four health regions of Burkina Faso: case control study. Pan Afr Med J. 2015;21:-152.

31. Namukwaya E, Nakwagala FN, Mulekya F, Mayanja-Kizza H, Mugerwa R. Predictors of treatment failure among pulmonary tuberculosis patients in Mulago hospital, Uganda. Afr Health Sci. 2011:11(Suppl 1):S105-11.

32. Kanabus, A. Information about Tuberculosis. Global Health Education, 2016 available at: http://www.tbfacts.org/tb-treatment/\#sthash.pKspH8BN.dpuf. Accessed 1/2/17. 